\title{
THE ROLE OF INTERACTIVE SCULPTURE IN ENRICHING CHILDREN'S IMAGINATION
}

Hanan Mohamed

Sculpture Department, Faculty of Art Education, Helwan University, Egypt

\begin{abstract}
One of the characteristics of interactive sculpture is the interaction between action and reaction. As it is a type of communication and interaction between the artist and the recipient, especially if this recipient is a child, that biological organism with a degree of privacy and distinction that brings together the psychologists of childhood and human development that the source of that uniqueness associated with it is due to the magnitude of the brain plasticity and it is natural that this characteristic has consequences. One of the most important of these is the superior and rapid ability to form new brain patterns capable of adapting to untried experiences, representing them, and dealing with them with flexibility and passion, as well as another characteristic associated with the child's brain plasticity, which is openness to the imaginary space, and non-compliance with stressful physical or social determinants that can be understood. The ability of cerebral malleability has in creating neural networks whose possible possibilities cannot be counted, and each of these possibilities is an opportunity to form a new imaginary world, and thus the interactive action becomes an important role in revealing the artist's ability to transform the artwork from a static structure to another open, carrying To enrich the imagination. Therefore, the research problem is determined in the following question: Is there a relationship between interaction with the sculptural work and enriching the imagination of the child? The study relies on the analytical and descriptive approach in both directions, the first: it examines the philosophical founding of interactive sculpture and its various plastic formulations, and the second: it examines the interactive competence between the child's imagination and the stages of forming concepts and perceptions, and the thinking patterns it contains based on mental imagination and perception, explaining this through multiple responses It is one of the advantages of interactive sculpture in activating different patterns of thinking and thus enriching the two types of thinking entrusted to the imagination in the context of communicative activity and the interactive context. And according to these directions. And to achieve the research goal, which is to uncover the role of interactive sculpture in enriching the imagination.

Keywords

Interactive, Sculpture, Enriching, Children, Imagination.
\end{abstract}

\section{Introduction:}

The essence of imagination and its relationship to each of the other mental processes are dealt with on the one hand and on the other side the link between the imagination and the sensoryemotional side of the child and the stages of formation of his perceptions. The stage of childhood is the beginning of the birth of the age of 18 years, according to the classification followed by the United States of America. Then the concept of interactive sculpture is addressed and its association with behavioral responses.

First: The concept of imagination: The imagination process is one of the basic processes that a person uses in his pursuit of new and unfamiliar ideas, perceptions and experiences, as it is an essential and effective element in the system of thinking and mental activity, and then it is almost a common process between curiosity and creativity, as it is a mental activity that works

* Corresponding author: art_education@helwan.edu.eg 
On collecting mental images of perceptual perceptions and reshaping them in a new way, which can be inferred by observing the apparent behavior that takes different forms in the child and contributes to achieving a state of psychological compatibility and behavioral elevation. Many Senses to Unified Concepts. "

In this context, Plato declares: "Through the imagination, the soul forms the substance, gives it life, and deals with the imagination as the place in which the ideal and the real, nature and the soul unite in an original way."

- Definition of imagination: The word Imaginaire and its translation of imagined is used in the language with at least three connotations, as an adjective, and it means that which exists only in the imagination, which has no real reality, as an object noun, to denote what was imagined, as a noun, and it means the thing produced by the imagination, as it means Imagination field. The concept itself extends its connotations through the plurality of different human sciences, "the word imagined is nothing but a synonym that better expresses the word fiction, and makes the latter open and enjoyable." In order to define and analyze the concept of the imaginary, it will be done by relying on two overlapping references, which are:

\section{1- Historical reference and conceptual reference:}

A- Plato: Imagination as a simulation: It is the relationship between what is apparent and what is a model. Likewise, the situation of the human being exchanged for images copies, images - simulacres, shadows, reflections and symbols, Plato expresses the moment in which the world of appearances is embodied, so that This world became presented as an analogy to the real reality of the model, and to the realm of meanings and real images, except that this likeness may be a close copy of the original (an icon), and it may be a distant, distorted copy (simulacre) that there is no existence, of an image without a real reality, and no existence This resulted in the establishment of a new situation represented in the middle position that the image occupies between existence and non-existence, between presence and absence, between the visible and the invisible. That is, the image has an evocative function. It does not appear from the thing that you simulate except the outward appearance, which is similar, because the act of learning is a recollection of a fact that had been contemplated before.

B- Aristotle: Imagination is considered an effective method: Aristotle is considered one of the first pioneers who gave the imagination a "major role in formation ID Totamin the subject matter of thought is described as a motor energy, operating within shapes and patterns, and it has become present as a basic mediator between thought, mind and feeling. "Aristotle makes the imagination a central axis between the two. He 
kept him from feeling, and made him independent of him despite his association with him, which explains the ability to produce images, diversify them, synthesize them, or test, examine and employ them. This confirms that the concepts are not pictures, although they are presented in the form of pictures. Every thought process, whatever its nature, is associated with images, and thus imagination plays the function of linking, connecting and synthesizing.

Imagination and feeling: the soul is an effective force in relation to the body since it is an organized and vital principle, whether in terms of nutrition, for example, or sensation. It is this sharing of feeling that makes the element of fantasy and desire permanently linked. Desire presupposes the imagination, and works to stimulate movement, because the feeling may be pleasure or pain. And the imagination, in turn, relates to a primary memory, which stores images and matches their immediate surroundings. However, man is distinguished, in addition, by the process of thinking and the selection of the image of memory. It moves from the level of experience to the level of creativity and science. " Common sense plays across the five senses - sight, hearing, smell, taste and touch. The function of perceiving the senses and making comparisons between the data of the sensation. It also gives the calculating subject the awareness of the sensation, and the imagination resides here in the synthetic role, and the mediator between the senses is related to the feeling and is separated from it at the same time. This is the state of the imagination, which is a specific extension of the sensation, meaning that the parameters of the sense are the condition of the imagination and its origin, it is positive, because it is a secondary movement resulting from the feeling, its continuation, and because it is a specific memory. Multiplicity also comes from it because it synthesizes the images of absent things. This visual power "finds what the senses cannot find at all, so it can synthesize the images, but the sense does not synthesize the image."

Imagination and thought: knowledge begins with feeling, and moves towards it by perception, and there is no knowledge except through the faculties. Hence, imagination overrides sensation to become a necessary condition of thought. In this context, Aristotle says, "The mind perceives the images of things by the way they become imagined, so that the perceived thing is either required, but escaped from it without feeling. The soul, then, can never think or understand without the presence of the images. The image is subordinate to the mind, by virtue of its compositional function, and by virtue of the fact that the thinking process does not take place without an imagination. Psychology for the word imagination, and for its dynamic role as a mediator between sensation and thought, as the energy of C - Espinosa and Kant, that Spinoza assigns the imagination a dynamic role related to daily human activity, so that it becomes 
associated with desire and the search for power, and thus imagination constitutes a source of primary knowledge. With a proactive role, as it contributes to finding positive solutions, and can only play this positive role in the case of the mind's intervention. There is therefore a duality in the function of the imagination as, on the one hand, it expresses the whims of the body, and on the other hand it is subordinate to the mind. This positive role can be linked to the imagination. In a basic Kantian concept, which he considers "a fundamental force at work L as a principle for all knowledge. "

Imagination is found in Kant in the middle between feeling and perception, as it is related to the queen of sensation with one of the extremes that plays the role of receiving, the forms of space and time. Hence it is, in turn, a negative recipient. However, imagination is active and active, just as the active faculty of understanding is considered the second party and is the queen of rules and concepts - because it plays the role of synthesis in time. The empirical fiction reproduces the images that have been collected within the queen of sense (recollection, association and synthesis), and a pure imagination, subject to the coincidence of individual experience. This structure of time (imagination) reveals the structure of the relationship with the external world, which is finite as long as man cannot limit and control the totality of experience. And he must rebuild the edifice of knowledge as a whole from the point of view of a limited faculty of understanding that seeks to attain the faculty of feeling that the subjects give, but does not allow her to think about it. On the other hand, Kant connects imagination with beauty, revealing the fertility of imagination. "Where he is freed from the concept to discover his freedom, because beauty drives more thinking, and if imagination, in objective knowledge, is subject to the constraints of understanding [...] then, on the other hand, it is free in an aesthetic perspective.

And because of the importance of the concept of time and space in shaping the human feeling of the child resulting from the senses, which is the first catalyst for the imagination, they had to be addressed by analysis. Real time lived (permanence) is characterized by several characteristics, including that:

Memory: it lasts, meaning that it preserves the events that it went through, so every moment the child lives is the fruit of previous moments that he lived, the present is a gathering of the past and an emanation, and this time can be likened to a colored liquid, such as adding a new drop to it that mixes with other drops. And it takes on a new color.

- Intertwined: the emotional states are not characterized by juxtaposition, but rather each window and intertwining state in the other, even successive states, overlap and reflect the whole soul. , Does not accept prediction, intuition is linked to its permanence is increasing, where 
perception is carried out continuously, novelty cannot be predicted. Every new emotional state is a moment of creativity., The succession of every psychological state that follows and follows another psychological state, and this does not mean that every emotional state erases the state that preceded it, while the succession that is characterized by permanence is a present that bears the characteristics of the past, carrying all the past and containing it. , Contact. There is no present psychological state that is separated and distinguished from the other, so every connection is uninterrupted, how. It is not measurable because the measurable is the quantity that is extended in space and characterized by discrete with which time withdraws from the outside and does not penetrate into depth. Synchronicity is (a mathematical instantaneous time, at which real time intersects with space. It is a time used by physicists, chemists, and astronomers, as it is a tool of scientific determinism and used in physical laws). Real time or permanence is the feature of the child's psychological life, so the inner emotional world is considered a qualitative change, A continuous period, overlapping phenomena that accept division, freedom that never ceases to be renewed and enriched. As for the place, it is characterized by change and does not preserve the real time except in the context of a conscious and poetic subject that has the ability to memorize all the different states of movement in the place, tribal and remote, that is, there is some kind of communication between. The past and present moment by the act of remembrance. The poet is the fabric of a moving, changing reality. Here freedom is achieved in that continuous permanence, as free action comes from the soul as a whole. It is an action issued by the character. It is characterized by confidence, reassurance, and will. Freedom is the essence of the permanence of the self, and assuming that the intensity of any emotional state must be identical to the amount of stimuli or the punch that I worked to create, but most of the time the effect or the result is spoken without knowing the extent of the stimulus or even its nature.

\section{Results:}

1- The traditional philosophical approach has consistently included the concept of imagination within the circle of knowledge, and it plays a formative role for understanding, and it helps the child to acquire a degree of intelligence and attention to reality.

2- The visualization process depends on the storage of memory and the mechanisms of memory in retrieving the information that the child maintains in his memory and links it to new formulas in the present and extends to the future.

3- The mental perception is the set of images that appear in front of the child when he is in front of a stimulant during which he is placed in the interactive situation and tries to summon it from his memory, which includes an accumulated storage of experiences, and these images 
are related to the activity of perceptual representations of the process of imagination that help to form mental images that do not exist in reality as well as It helps in forming abstract concepts, as mental images are derived from past experiences and memories, and that children differ in terms of creating these images, some are predominantly visual images, and others are predominantly auditory, as well as kinetic, gustatory, olfactory, organic, and skin images, and these images are the material. From which the visualization process derives its work.

4- The interactive action is an activity based on an intellectual system linked to the will and consciousness, and this action is achieved through three dimensions: the human dimension, the intellectual dimension, and the understanding dimension.

5- The interactive act of the artist is achieved by activating the mind on the action in order to direct towards understanding with the recipient (the child).

6- Postmodern artwork achieves its interactive efficiency in its openness and communication with others, and the artwork becomes productive, open-minded thanks to its capacity for assimilation. Interpretations with multiple responses.

7 - The recipient (the child) achieves his effective efficiency at the moment of receiving the artistic work, by linking the internal components of the artistic work with the components of the living world.

\section{Recommendations:}

1- Expanding the adoption of the ideological approach based on interactive sculpture as it is based on the recipient (the child) who is able to think. And discovery. And the ability to use imagination. Thus, the provision of an integrated system that guarantees the developmental value of innovation and knowledge.

2- Adopting intellectual trends based on activating the role of imagination in the child because of its enabling access to the means of acquiring knowledge, and opening horizons for interaction with contemporary high data.

3- The ability to create interactive works on the Egyptian street, to build a system of positive cultural values in the Egyptian society, that respects diversity and difference, and gains the ability to free choice.

4- Adopting environmental studies related to interactive sculpture in the field of enriching the imagination among children.

\section{References:}

1) Saidi Abdel-Fattah: the concept of time between Bergson and Einstein. Published Master of Philosophy thesis. University of the Brotherhood of Constantine, Faculty of Humanities and Social Sciences, 2008, p. 58. 
2) Zakaria Ibrahim: Henri Yerguson, second edition, Dar Al Ma'arif, Egypt, Cairo, pp. 2-3.

3) Mahfouz Soheir Anwar: The Mental Imagination of University Students in Its Relation to the Cognitive Style, The Egyptian Journal of Psychological Studies, No. 8, 1994.

4) Khalifa Abd al-Latif Muhammad: The relationship of imagination to both curiosity and creativity in the middle school sample of education stage students, The Arab Magazine, First Issue. (1994).

5) Zaghloul Rafi Al-Naseer, Al-Zaghoul Emad Abdel-Rahim Cognitive Psychology, AlShorouk Publishing House, Amman, Jordan. 2008.

6) Sahibzuhair and others, Arsat in the Architecture of Art, Baghdad, 2008.

7) 7 - Magdy Abdel Karim Hayeb, Self-thinking and the innovative features associated with multi-dimensional thinking among undergraduate students, Egyptian Book Authority Publications, Issues 41 and 40 Cairo (17).

8) Shaker Abdul-Hamid: The Age of Image, Pros and Cons, Issue 311, Alam Al-Ma rifah, Kuwait, 2005.

9) Bonnecque et Cauet, Dictionnaire LATIN-FRANCAIS, Ed., Belin, Paris, 1967 .

10) Hélène Védrine. Les grandes conceptions de l'imaginaire, Biblio, Essais, Paris, 1990.

11) Jean Pierre Vernant, Religions, histoires, raisons. Petite Collection. Maspéro. Paris, 1979.

12) Davis. Susan Danielsn Ghee: The Imagery - Creativity Connedon, The Journal of Creative Nu 3, Third Quarter Behaviar, (1994) Vol 28.

13) Sternberg, R. Cognitive Psychology. 3rd Edition. Thomson - Wadsworth, Australia(2003)

14) Henri Bergson : Matière et mémoire, Essai sur la relation du corps à l'esprit, PUF, 1965, 72e edition.

15) Bosseur Jean-Yves: Vocabulaire des Arts Plastiques du xxe Siecle. Edition Minerve,1998.

16) David Z. Saltez: The Art of Interactive. The Journal of Aesth and Art Critisim 55:2 Spring, 1996.

17) Noha Sayed Mohamed AFIFI, Arafa Shaker HASSAN, PRODUCTION AN EXTERNAL CLADDING UNITS USING RUBBER MOLD AND POLYESTER, International Journal of Multidisciplinary Studies in Art and Technology, Vol. 3, No. 1, 2020, pp. 1-6.

18) Hadeel Muhammad Aziz Nazmi SALEM, SPECIFIC SELECTIVE MEDIA INSPIRING IDEAS OF VISUAL EXPRESSION IN THE ARTISTIC SPACE: AN APPLIED STUDY IN THE FIELD OF PAINTING FOR THE INTERPHONE AND TRANSIENT EXHIBITION "THE MEDIUM SURVIVAL AND THE SURFACE IS A VISUAL PASSION", International Journal of Multidisciplinary Studies in Art and Technology, Vol. 
3, No. 1, 2020, pp. 7-11.

19) Ghadeer ELMAYAH, TAKING ADVANTAGE OF THE TEXTILE INFLUENCES TO ADD THE DIMENSION OF CONCRETE TO THE WORKS OF THE ARTIST (CLAUDE MONET), International Journal of Multidisciplinary Studies in Art and Technology, Vol. 3, No. 1, 2020, pp. 12-13.

Received: September 15, 2020

Accepted: November 20, 2020 